\title{
СТРУКТУРА КОМПОЗИТОВ НА ОСНОВЕ МНОГОСТЕННЫХ УГЛЕРОДНЫХ НАНОТРУБОК И ОКСИДА ОЛОВА
}

\author{
(C)2018 С. Н. Несов ${ }^{1}$, П. М. Корусенко ${ }^{1}$, В. В. Болотов ${ }^{1}$, С. Н. Поворознюк ${ }^{1,2}$, К. Е. Ивлев ${ }^{1}$ \\ ${ }^{1}$ Омский научный цฺентр Сибирского отделения РАН, пр. К. Маркса, 15, 644024 Омск, Россия \\ ${ }^{2}$ Омский государственный технический университет, пр. Мира, 11, 644050 Омск, Россия \\ e-mail:nesov55@mail.ru
}

Поступила в редакцию 27.03.2018

\begin{abstract}
Аннотация. Методами рентгеноэлектронной спектроскопии и сканирующей электронной микроскопии исследована морфология, структура и состав композитов на основе многостенных углеродных нанотрубок и оксида олова, сформированных с применением двух различных методов для осаждения оксида олова: метода химического газофазного осаждения и метода магнетронного распыления. Полученные данные позволили изучить особенности дефектообразования и изменения химического состояния углерода в стенках многостенных углеродных нанотрубок в процессе формирования композитов, а также исследовать тип взаимодействия оксида олова с внешними стенками углеродных нанотрубок на межфазных интерфейсах композитов, сформированных различными методами.
\end{abstract}

Ключевые слова: многостенные углеродные нанотрубки, композит, оксид олова, химическое газофазное осаждение, магнетронное распыления, рентгеновская спектроскопия.

DOI: https://doi.org/10.17308/kcmf.2018.20/515

\section{ВВЕДЕНИЕ}

Оксиды олова $\mathrm{Sn}(\mathrm{IV})$ и $\mathrm{Sn}(\mathrm{II})$ являются хорошо изученными полупроводниковыми оксидами, которые используются при производстве чувствительных элементов газовых сенсоров, оптических устройств, светоизлучающих диодов [1], а также перспективны при разработке электродов литий-ионных аккумуляторов с высокой удельной емкостью [2]. Повышение требований к современным приборам и устройствам стимулирует разработку новых композитных материалов, которые будут обладать более высокими функциональными характеристиками. Одним из направлений получения новых материалов является разработка композитов на основе массивов углеродных нанотрубок (УНТ), декорированных слоями либо наночастицами оксидов металлов. Выбор массивов УНТ в качестве матрицы для создания композитов обусловлен их колоссальным аспектным соотношением (более $1000 \mathrm{~m}^{2} /$ г) и высокими механическими характеристиками (прочность и упругость) [3]. Распределение оксида олова по поверхности многостенных УНТ (МУНТ) позволяет получать новый материал, обладающий большой удельной площадью поверхности и ме- ханической устойчивостью к циклическим нагрузкам различного характера (механическим, температурным и т. д.).

Для получения наноструктурированных композитных материалов на основе УНТ и оксидов металлов зачастую адаптируют уже известные методы формирования слоев, наночастиц и покрытий металлов и их оксидов [4]. Очевидно, что морфология и структура, а, следовательно, и физико-химические характеристики таких композитов, в первую очередь, будут зависеть от выбранного метода и режимов их формирования. Одним из определяющих моментов в данном случае является изменение структурно-химического состояния внешних стенок МУНТ в процессе формирования композита.

Для анализа наноструктурированных композитных материалов, которые зачастую обладают градиентной структурой и составом, необходимо применять комбинации методов исследования, обладающих различной глубиной анализа. Корректный анализ локальной атомной и электронной структуры таких композитов, а также структуры их межфазных интерфейсов возможен с использованием комбинации методов электронной микроскопии 
и поверхностно-чувствительных рентгеноэлектронных методов: рентгенофотоэлектронной (X-ray photoelectron spectroscopy - XPS) и рентгеновской спектроскопии поглощения (X-ray Absorption Near Edge Spectroscopy - XANES) [5, 6].

В настоящей работе с применением методов сканирующей электронной микроскопии (Scanning Electron Microscopy - SEM), энергодисперсионной рентгеновской спектроскопии (Energy-dispersive X-ray spectroscopy - EDX), XPS и XANES проведен сравнительный анализ морфологии и структуры композитов на основе массивов МУНТ и оксида олова, сформированных с использованием магнетронного распыления и химического газофазного осаждения оксида олова на поверхность углеродных нанотрубок. Исследована структура, химическое состояние поверхности и интерфейсов «оксид олова-МУНТ» в композитах.

\section{ЭКСПЕРИМЕНТАЛЬНАЯ ЧАСТЬ}

Массивы углеродных нанотрубок были синтезированы методом каталитического паро-фазного осаждения (Catalysis Chemical Vapor Deposition) на подложках монокристаллического кремния с поверхностным термическим оксидом при температуре $800{ }^{\circ} \mathrm{C}$. В качестве реакционной смеси был использован раствор ацетонитрила с ферроценом в объемном соотношении 100:2. Толщина слоя МУНТ составляла $\sim 15 \pm 2$ мкм. Диаметр синтезированных МУНТ составлял 40-60 нм. Полученные МУНТ содержали в составе 2-3 ат.\% азота, который встроен в структуру стенок МУНТ в виде пиридиновых, пирольных и графитоподобных дефектов, а также присутствует в молекулярном состоянии $\left(\mathrm{N}_{2}\right)$ в межстеночном пространстве и в полостях углеродных нанотрубок [7].

Синтез композитов $\mathrm{SnO}_{\mathrm{x}} / \mathrm{MУНТ} \mathrm{методом} \mathrm{хи-}$ мического газофазного осаждения проводился путем термического разложения кристаллогидратов $\mathrm{SnCl}_{2} \cdot 2 \mathrm{H}_{2} \mathrm{O}$ при температуре $550^{\circ} \mathrm{C}$ с последующим осаждением паров на подложку с массивом МУНТ, разогретую до температуры $340{ }^{\circ} \mathrm{C}$. Для удаления остатков хлора, присутствующих в композитах в виде неразложившихся хлоридов олова и соляной кислоты, композиты дополнительно просушивались при температуре $150{ }^{\circ} \mathrm{C}$ в атмосфере аргона.

При синтезе композитов методом магнетронного распыления проводилось распыления металлического олова (чистотой $99.9 \%$ ) в аргоно-кислородной атмосфере при давлении 0.1 Па. Значение тока разряда составляло 100 мА, значение ускоряющего напряжения составляло 500 В.
Для анализа динамики осаждения оксида металла на поверхность МУНТ были синтезированы композиты с различным содержанием оксида олова. В случае химического осаждения количество оксида регулировалось массой испаряемой навески кристаллогидратов $\mathrm{SnCl}_{2} \cdot 2 \mathrm{H}_{2} \mathrm{O}$. Были использованы навески с массами, различающимися в 2 раза: 0.3 мг - Режим-1 и 0.6 мг - Режим-2. В случае формирования композита $\mathrm{SnO}_{\mathrm{x}} / \mathrm{MУНТ} \mathrm{методом} \mathrm{магнет-}$ ронного распыления количество оксида олова регулировалось изменением времени процесса. Режим-1 - соответствует композиту, сформированному при 10 минутах магнетронного распыления; Режим-2 - при 20 минутах. Другие условия (температура, давление, состав атмосферы) при синтезе композитов при различных режимах оставались аналогичными.

Анализ структуры и морфологии полученных композитов методом SEM проводился с использованием электронного микроскопа JEOL JSM 6610 LV в центре коллективного пользования ОНЦ CO РАН (ОмЦКП СО РАН, г. Омск). ЕDХ анализ был осуществлен на микроскопе JEOL JSM 6610 LV с использованием приставки INCA-350 Oxford Instruments. Диаметр зондирующего пучка электронов при исследовании методом EDX составлял > 1.5 мкм, а глубина анализа до 15 мкм.

Изучение атомной и электронной структуры композитов методами XPS и XANES было проведено с использованием оборудования экспериментальной станции RGL-PES на синхротронном накопительном кольце BESSY II (г. Берлин, Германия). Измерения XPS спектров проводились с помощью полусферического анализатора Phoibos 150 при энергии фотонов возбуждающего излучения 850 эВ. Спектры XANES регистрировались в режиме измерения тока утечки с образца. Глубина анализа методом XPS составляла 1-2 нм, методом XANES 10 нм [8].

\section{РЕЗУЛЬТАТЫ И ИХ ОБСУЖДЕНИЕ}

\section{Морфология, структура и состав композитов по данным SEM и EDX}

Результаты анализа SEM изображений композитов $\mathrm{SnO}_{\text {х }}$ МУНТ, сформированных методом химического газофазного осаждения (рис. 1) показал, что оксид олова распределен по поверхности МУНТ в виде отдельных кластеров, обладающих близкими линейными размерами 20-50 нм при использовании Режима-1 (рис. 1a) и 100 нм в случае Режима-2 (рис. $1 b$ ). Близкие линейные размеры кластеров указывают на то, что процесс осаждения оксида 


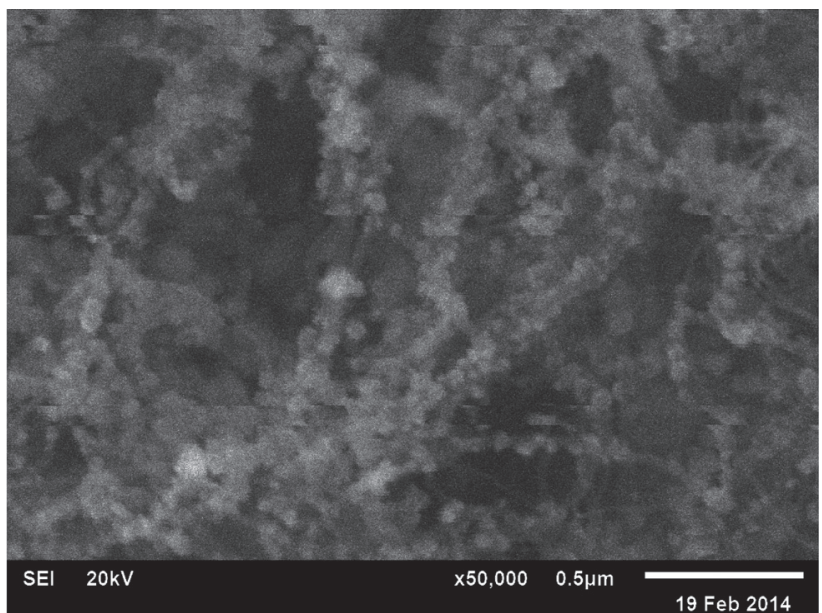

$a$

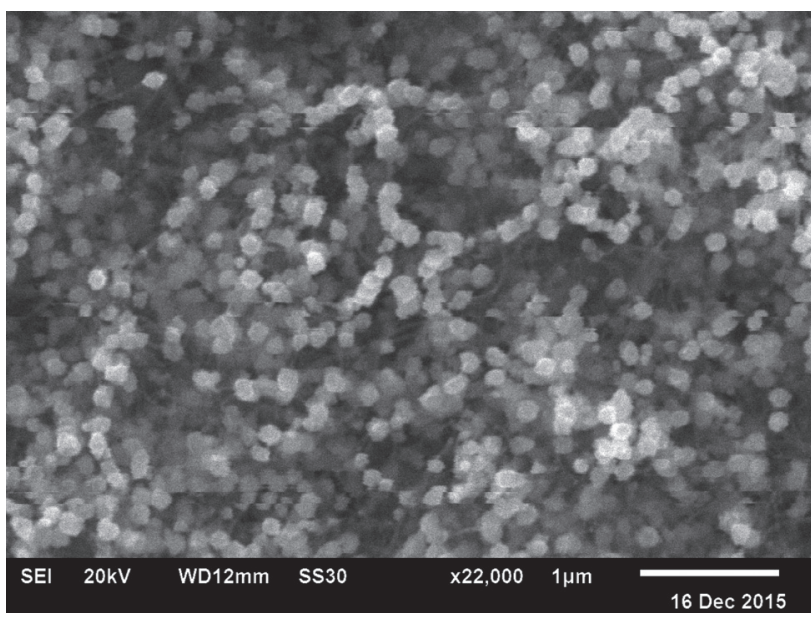

$b$

Рис. 1. SЕM изображения композитов $\mathrm{SnO} / \mathrm{MУНТ,} \mathrm{сформированных} \mathrm{методом} \mathrm{химического} \mathrm{осаждения}(a)-$ Режим-1; $(b)$ - Режим-2

[Fig. 1. SEM images of $\mathrm{SnO}_{\mathrm{x}} / \mathrm{MWCNTs}$ composites formed by the chemical gas-phase deposition method $(a)$ - Mode$1 ;(b)-$ Mode-2]

олова из газовой фазы, протекает достаточно равномерно. Кластерная структура композита позволяет предполагать достаточно слабое взаимодействие оксида олова с внешними стенками МУНТ. По-видимому, первоначальное формирование зародышей кластеров оксида олова происходит на участках МУНТ, обладающих дефектами кристаллического строения. Далее осаждение оксида олова происходит преимущественно на сформированных зародышах, в результате чего формируются кластерная структура композита со свободными от олова и его оксидов участками поверхности МУНТ.

При формировании композитов методом магнетронного распыления оксид олова достаточно

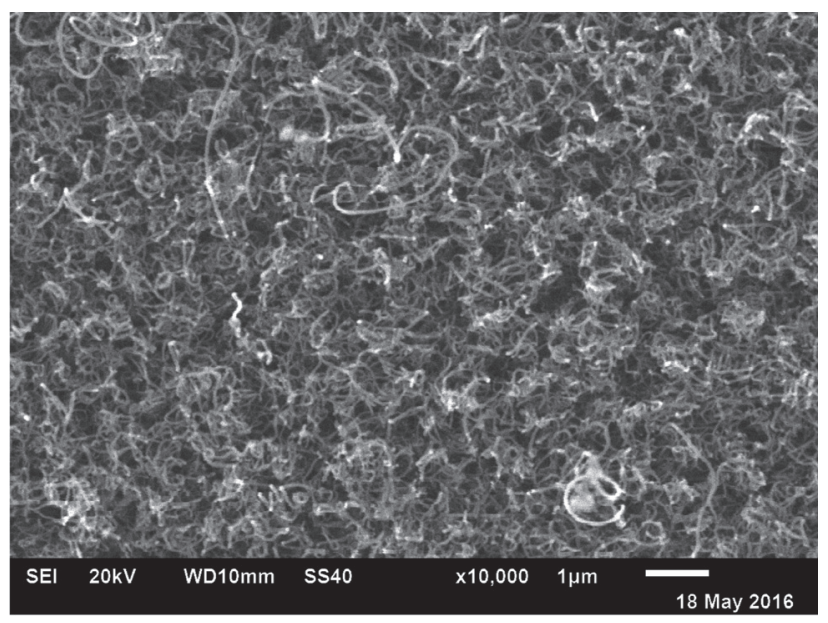

$a$ равномерно распределяется по поверхности отдельных МУНТ, покрывая их в виде сплошного слоя (рис. 2). При этом в межтрубочном пространстве массива углеродных нанотрубок не наблюдается формирования каких-либо кластерных образований оксида олова. Увеличение времени процесса формирования композита приводит к увеличению толщины слоя оксида олова на поверхности отдельных МУНТ. Формирование сплошного равномерного слоя оксида олова на поверхности МУНТ может указывать на более высокую межфазную адгезию в композите, сформированном данным методом. Высокая адгезия металлоксидного компонента к поверхности МУНТ в данном случае позволяет

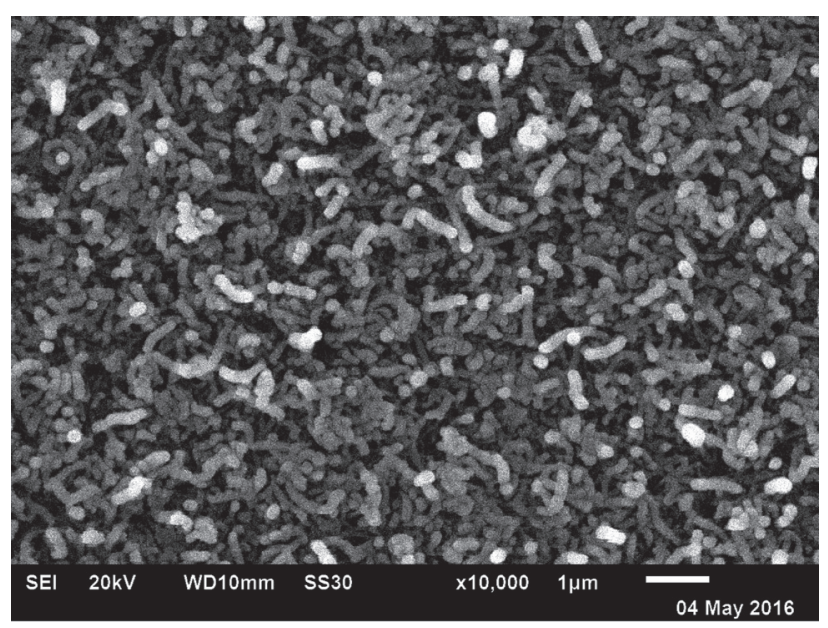

$b$

Pис. 2. SEM изображения композитов $\mathrm{SnO}_{\mathrm{x}}$ МУНТ, сформированных методом магнетронного распыления $(a)-$ Режим-1; (b) - Режим-2

[Fig. 2. SEM images of $\mathrm{SnO}_{x} / \mathrm{MWCNTS}$ composites formed by the magnetron sputtering method $(a)$ - Mode-1; $(b)-$ Mode-2] 
предполагать изменение структурно-химического состояния углерода в стенках МУНТ в процессе магнетронного распыления, поскольку известно, что поверхность МУНТ (без проведения какойлибо функционализации) слабо взаимодействует с металлами и их оксидами [9].

Для дальнейшего анализа структуры, состава и химического состояния композитов (EDX, XPS, XANES), сформированных методом магнетронного распыления, был выбран композит с меньшим содержанием оксида олова. Это позволило исследовать структуру и химический состав оксида олова на поверхности, а также провести корректный анализ состояния внешних стенок МУНТ в композите. По нашим оценкам для композита, сформированного методом магнетронного распыления при Режиме-1 (рис. 2a) толщина слоя оксида олова на поверхности МУНТ лежит в диапазоне 2.5-5 нм, что сопоставимо с глубиной анализа поверхностночувствительных методов XPS и XANES. Для анализа методами EDX, XPS, XANES структурно-химического состояния композитов, полученных химическим осаждением, был использован композит, полученный при Режиме-2, поскольку по данным SEM (рис. 1), при использовании данного режима в композите имеется достаточное количество участков поверхности МУНТ, не покрытых кластерами оксида олова.

В табл. 1 представлены результаты количественного элементного анализа состава композитов методом EDX. Видно, что в составе композитов, полу- ченных методами, как химического осаждения оксида олова, так и магнетронного распыления, присутствуют углерод, кислород и олово. Это указывает на достаточно высокую чистоту процессов получения композитов. Наличие кремния в результатах анализа связано с тем, что глубина анализа методом EDX превышает толщину слоёв МУНТ, на которых были сформированы композиты. В табл. 1 приведено также отношение атомарных концентрации кислорода к концентрации олова в композитах. Данная величина не является коэффициентом стехиометрии оксида олова, однако позволяет провести оценку химического взаимодействия элементов в составе композитов. Как видно из данных табл. 1, концентрация олова в композитах, полученных методами химического осаждения и магнетронного распыления, значительно различается. Низкое содержание олова в композите, сформированном методом магнетронного распыления, обусловлено, по-видимому, его распределением только в приповерхностной области массива МУНТ. При этом анализ методом EDX дает усреднение сигнала по всей глубине массива МУНТ. При формировании композита методом химического газофазного осаждения газообразные пары прекурсора оловянного оксида легко проникают в пористый слой МУНТ, благодаря чему оксид олова распределяется в приповерхностной области большей толщины, чем в случае получения композита методом магнетронного распыления.

Значение соотношения [O]/[Sn] (табл. 1) показывает, что в композитах, наблюдается избыточное

Таблица 1. Результаты количественного элементного анализа композитов $\mathrm{SnO}_{\mathrm{x}} / \mathrm{MУHT,} \mathrm{сформированных}$ методами химического газофазного осаждения и магнетронного распыления, по данным EDX

[Table 1. Results of quantitative elemental analysis of the $\mathrm{SnO}_{\mathrm{x}} / \mathrm{MWCNTs}$ composites formed by the methods of chemical gas-phase deposition and magnetron sputtering, according to EDX]

\begin{tabular}{|c|c|c|c|c|c|}
\hline \multicolumn{6}{|c|}{$\begin{array}{l}\text { Композит } \mathrm{SnO}_{\mathrm{x}} / \mathrm{MУHT,} \mathrm{сформированный} \mathrm{методом} \mathrm{химического} \mathrm{осаждения} \\
\text { [Composite } \mathrm{SnO}_{\mathrm{x}} / \mathrm{MWCNTs} \text {, formed by chemical gas-phase deposition] }\end{array}$} \\
\hline \multirow{2}{*}{$\begin{array}{l}\text { no. точки } \\
\text { [no. point] }\end{array}$} & \multicolumn{4}{|c|}{$\begin{array}{l}\text { Концентрация, ат.\% } \\
\text { [Concentration, at.\%] }\end{array}$} & \multirow{2}{*}[\mathrm{O}]{$/[\mathrm{Sn}]$} \\
\hline & {$[\mathrm{C}]$} & [O] & [Sn] & {$[\mathrm{Si}]$} & \\
\hline 1 & 77.7 & 15.4 & 5.1 & 1.8 & 3.0 \\
\hline 2 & 76.9 & 16.4 & 5.1 & 1.6 & 3.3 \\
\hline 3 & 77.4 & 15.9 & 5.1 & 1.6 & 3.1 \\
\hline \multicolumn{6}{|c|}{$\begin{array}{c}\text { Композит } \mathrm{SnO}_{\mathrm{x}} / \mathrm{MУHT,} \mathrm{сформированный} \mathrm{методом} \mathrm{магнетронного} \mathrm{распыления} \\
\text { [Composite } \mathrm{SnO}_{\mathrm{x}} / \mathrm{MWCNTs} \text {, formed by the method of magnetron sputtering] }\end{array}$} \\
\hline \multirow{2}{*}{$\begin{array}{l}\text { nо. точки } \\
\text { [no. point] }\end{array}$} & \multicolumn{4}{|c|}{$\begin{array}{l}\text { Концентрация, ат.\% } \\
\text { [Concentration, at.\%] }\end{array}$} & \multirow{2}{*}[\mathrm{O}]{$/[\mathrm{Sn}]$} \\
\hline & {$[\mathrm{C}]$} & {$[\mathrm{O}]$} & {$[\mathrm{Sn}]$} & {$[\mathrm{Si}]$} & \\
\hline 1 & 90.4 & 7.4 & 0.3 & 1.9 & 24.6 \\
\hline 2 & 90.1 & 8.0 & 0.3 & 1.6 & 26.7 \\
\hline 3 & 90.1 & 7.8 & 0.4 & 1.7 & 19.5 \\
\hline
\end{tabular}


содержание кислорода, что позволяет говорить об окислении поверхности МУНТ в процессе формирования композитов. При этом значительно более высокое значение указанного отношения для композита, полученного магнетронным распылением, позволяет говорить о более сильном окислении поверхности МУНТ.

\section{Состав композитов по данным XPS}

На рис. 3 приведены обзорные XPS спектры композитов, сформированных различными методами. Метод XPS при использовании возбуждающих квантов с энергией 850 эВ позволяет анализировать тонкий поверхностный слой, толщиной $~ 1-$ 2 нм. В спектрах композитов присутствуют линии кислорода, олова и углерода. В спектре композита, полученного методом химического осаждения (рис. 3, кривая 1), наблюдается более интенсивная линия углерода, что связано, по-видимому, с наличием в поверхностном слое композита участков поверхности МУНТ не покрытых кластерами оксида олова. В табл. 2 представлены результаты количественного элементного анализа композитов, выполненного с использованием интегральных площадей XPS линий, выделенных штриховой областью на рис. 3 .

Как видно из табл. 2 для композита, полученного методом химического осаждения, концентрация элементов, а также значение отношения концентраций $[\mathrm{O}] /[\mathrm{Sn}]$ достаточно близки к значениям, полученным по данным EDX (табл. 1). Совпадение результатов объемно-чувствительного (EDX) и поверхностно-чувствительного (XPS) методов анализа свидетельствует о достаточно равномерном по глубине составе композита. При этом для композита, полученного методом магнетронного распыления, результаты количественного анализа по данным XPS (табл. 2) существенно расходятся с данными EDX (табл. 1). Это указывает на значительный градиент состава композита по глубине и подтверждает, что осаждение оксида металла на поверхность углеродных нанотрубок при использовании магнетронного распыления происходит в тонком приповерхностном слое массива МУНТ. Отметим, что при анализе данного композита методом XPS основной вклад в спектр вносят электроны, эмитированные из слоя оксида олова, распределенного по поверхности МУНТ. При этом значение отношения [O]/[Sn], полученное по данным XPS (табл. 2), указывает, что в тонком поверхностном слое не наблюдается значительного избытка кислорода, который был обнаружен при анализе методом EDX. Данный результат позволяет предположить, что избыток кислорода, наблюдаемого по данным EDX, (табл. 1), связан с окисленным состоянием поверхности МУНТ под слоем металлоксидного компонента, а также с возможным окисле-

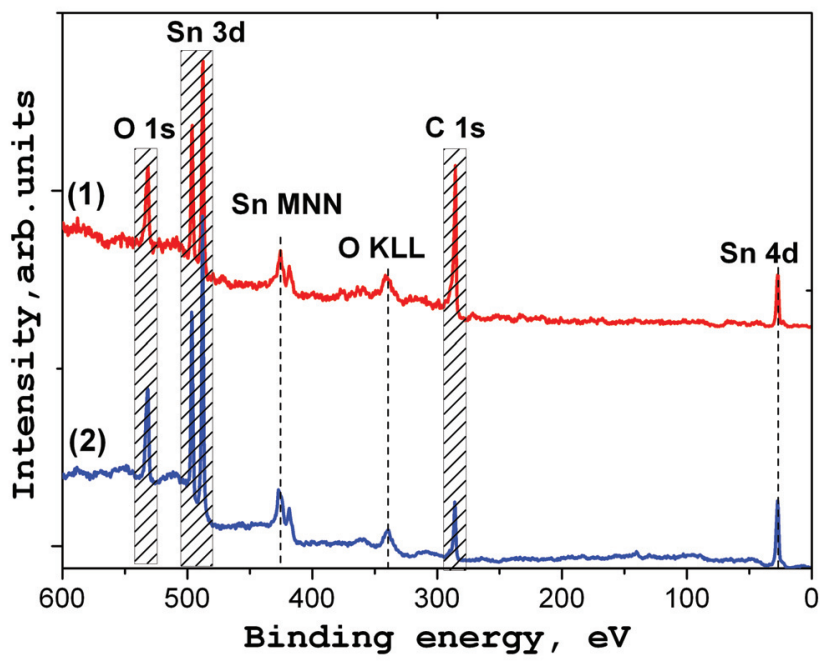

Рис. 3. Обзорные XPS спектры композитов $\mathrm{SnO}_{\mathrm{x}} /$ МУНТ: (1) - сформированного методом химического газофазного осаждения; (2) - методом магнетронного распыления

[Fig. 3. Survey XPS spectra of $\mathrm{SnO}_{\mathrm{x}} / \mathrm{MWCNTs}$ composites: (1) - formed by chemical gas-phase deposition; (2) formed by the method of magnetron sputtering]

Таблица 2. Результаты количественного элементного анализа композита $\mathrm{SnO}_{\mathrm{x}} / \mathrm{MУHT,} \mathrm{сформированных}$ методами химического газофазного осаждения и магнетронного распыления, по данным XPS

[Table 2. Results of quantitative elemental analysis of the $\mathrm{SnO}_{\mathrm{x}} / \mathrm{MWCNTs}$ composites formed by the methods of chemical gas-phase deposition and magnetron sputtering, according to XPS]

\begin{tabular}{|c|c|c|c|c|}
\hline \multirow{2}{*}{$\begin{array}{c}\text { Метод формирования композита } \\
\text { [Method of forming the composite] }\end{array}$} & \multicolumn{3}{|c|}{$\begin{array}{c}\text { Концентрация, ат.\% } \\
\text { [Concentration, at.\%] }\end{array}$} & [O]/[Sn] \\
\cline { 2 - 5 } & {$[\mathrm{C}]$} & {$[\mathrm{O}]$} & 6.9 & 3.1 \\
\hline $\begin{array}{c}\text { Химическое газофазное осаждение } \\
\text { [chemical gas-phase deposition] }\end{array}$ & 72.0 & 21.1 & 15.0 & 2.5 \\
\hline $\begin{array}{c}\text { Магнетронное распыление } \\
\text { [magnetron sputtering] }\end{array}$ & 47.6 & 37.4 & \\
\hline
\end{tabular}


нием углеродных нанотрубок в процессе получения композита на глубине, превышающей толщину сформированного композитного слоя.

\section{Структура композитов по данным XANES}

Детальный анализ атомной и электронной структуры композитов был проведён с использованием метода XANES. Метод XANES обладает высокой чувствительностью к локальному окружению и химическому состоянию атомов и обладает глубиной анализа, позволяющей снизить вклад поверхностных оксидов при анализе химического состояния олова, а также получить информацию о структуре внешних стенок МУНТ на интерфейсах «оксид олова - поверхность МУНТ».

На рис. 4 представлены XANES C K-спектры исходных МУНТ, а также композитов $\mathrm{SnO}_{\text {/ }}$ МУНТ, сформированных различными методами. Спектр поглощения К-края углерода отражает переходы с остовного $\mathrm{C} 1 s$ уровня на незанятые С $2 s, 2 p$ состояния $\pi *$ - и $\sigma *$-симметрии [ 10 , 11]. Интенсивные максимумы А и В в спектре исходных МУНТ (рис. 4, кривая 1), расположенные на энергиях фотонов 285.3 и 292 эВ, отвечают $\pi^{*}(\mathrm{C}=\mathrm{C})$ - и $\sigma^{*}(\mathrm{C}=\mathrm{C})$-состояниям углерода, входящего в состав стенок МУНТ. Соотношение интенсивности данных максимумов, а также наличие характерной тонкой структуры (2 локальных максимума $\mathrm{B}$ и $\mathrm{C})$ в структуре $\sigma^{*}(\mathrm{C}=\mathrm{C})$-резонанса указывает на достаточно высокую степень

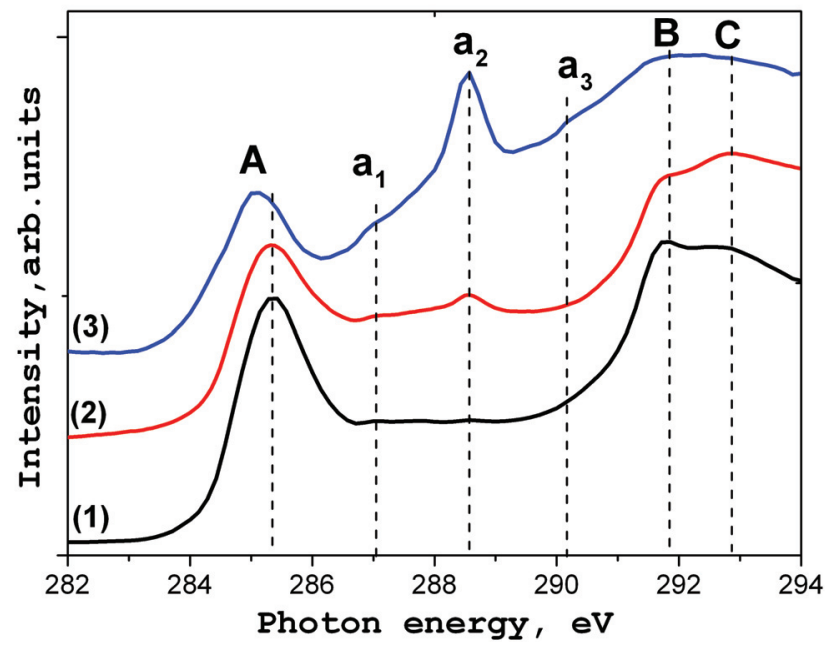

Рис. 4. Спектры XANES C К-края: 1 - исходного массива МУНТ; 2 - композита, сформированного методом химического осаждения; 3 - композита, сформированного методом магнетронного распыления

[Fig. 4. XANES C K-edge spectra: 1 - the initial MW-

CNTs; 2 - composite formed by the chemical gas-phase deposition method; 3 - composite formed by the magnetron sputtering method] графитизацции углерода в стенках углеродных нанотрубок $[10,12]$.

B XANES спектре композита, сформированного методом химического осаждения (рис. 4, кривая 2), наблюдается некоторое понижение относительной интенсивности $\pi^{*}(\mathrm{C}=\mathrm{C})$-резонанса, а также изменение тонкой структуры максимума, отвечающего $\sigma^{*}(\mathrm{C}=\mathrm{C})$-состояниям углерода. Это указывает на небольшое искажение локальной атомной структуры в стенках МУНТ. Наличие слабоинтенсивного максимума ( $\mathbf{a}_{2}$ ) на энергиях фотонов $\sim 288.7$ эВ свидетельствует о достаточно слабом окислении поверхности МУНТ в композите с образованием карбонильных $(\mathrm{C}=\mathrm{O})$ и карбоксильных групп (COOH) [13].

B XANES спектре композита, сформированного методом магнетронного распыления (рис. 4, кривая 3), отмечается значительное снижение интенсивности $\pi^{*}(\mathrm{C}=\mathrm{C})$-резонанса, сдвиг его максимума в низкие энергии связи, потеря тонкой структуры спектра $\sigma^{*}(\mathrm{C}=\mathrm{C})$-резонанса, а также присутствие дополнительных состояний в диапазоне энергий связи 286-291 эВ. Все это свидетельствует о высокой степени дефектности кристаллической структуры и окислении углерода в стенках МУНТ в данном композите. Наиболее высокоинтенсивный максимум ( $\mathbf{a}_{2}$ ) на энергиях фотонов $\sim 288.7$ эВ указывает на присутствие большого количества карбонильных и карбоксильных групп $(\mathrm{C}=\mathrm{O}, \mathrm{COOH})$. Состояния $\left(\mathbf{a}_{1}\right)$ на энергиях фотонов указывают на присутствие углерода в С-ОН связях в составе спиртовых и фенольных групп [13, 14]. Высокая интенсивность спектра в энергетическом диапазоне 289-291 эВ, а также наличие локальной особенности $\left(\mathbf{a}_{3}\right)$ на энергии фотонов $\sim 290.4$ эВ указывает на присутствие кислородсодержащих функциональных групп, содержащих углерод-кислородные цепочки с одинарными (C-O) связями. Состояния в данном диапазоне указывают на присутствие эпоксидных (C-O-C), эфирных (C-O), карбонатных (-CO $\mathrm{CO}_{3}$ групп [13-15]. Присутствие таких функциональных групп на поверхности МУНТ может приводить к формированию химических связей между внешними стенками МУНТ и оксидом металла (Ме-О-С связи) [6, 16-17]. Вывод о возможном химическом взаимодействии компонентов композита на межфазных интерфейсах хорошо согласуется с результатами SEM анализа композита, который показал высокую адгезию оксида олова к стенкам МУНТ.

Изменения структуры и химического состояния углерода в стенках МУНТ при осаждении оксида олова с использованием метода магнетронного распыления вероятнее всего обусловлены достаточно 
высокой энергией осаждаемых частиц. Известно, что энергия распыленных атомов металлических мишеней при магнетронном распылении лежит в диапазоне $\sim 10-30$ эВ, а энергия обратно рассеянных атомов и ионов рабочего газа, которые также воздействуют на подложку, может достигать $~ 100$ эВ. Доля таких частиц достигает $20 \%$ от всех ионов, попадающих на металлическую мишень $[18,19]$. Следовательно, энергия частиц, воздействующих на поверхность МУНТ, сравнима с энергией формирования вакансионных дефектов (энергия формирования моновакансии 7.8 эВ) [20]. Таким образом, в процессе формирования композита методом магнетронного распыления вполне вероятными являются процессы смещения атомов углерода из узловых положений в графитовой структуре стенок МУНТ, формирование вакансий, адатомов, междоузельных атомов и более крупных комплексов структурных дефектов (вакансионных кластеров). Это приводит к закреплению на дефектной поверхности МУНТ кислорода в виде различных функциональных групп, что обеспечивает высокую межфазную адгезию в композите, в том числе и за счет возможного ковалентного взаимодействия на межфазных интерфейсах.

На рис. 5 приведены XANES спектры Sn Mкрая композита $\mathrm{SnO}_{\mathrm{x}} / \mathrm{MУHT}$, сформированных различными методами. В качестве эталона мы использовали спектр порошка кристаллического $\mathrm{SnO}_{2} \mathrm{c}$ тетрагональной решеткой (рис. 5, кривая 1). Как видно XANES спектр олова композита, сформированного методом химического осаждения (рис. 5, кривая 2), достаточно близок по форме к спектру кристаллического $\mathrm{SnO}_{2}$, что свидетельствует о преобладании кристаллического диоксида олова с тетрагональной решеткой в металлоксидных кластеpax композита. Однако наличие предкраевой особенности спектра $\left(\mathbf{A}_{1}\right)$ указывает на наличие определенного количества вакансий кислорода в составе оксида олова [21-23].

Спектр Sn M-края композитов $\mathrm{SnO}_{\mathrm{x}} / \mathrm{MУHT}$, сформированного методом магнетронного распыления (рис. 5, кривая 3), существенно отличается от спектра кристаллического $\mathrm{SnO}_{2}$. Спектр не обладает тонкой структурой и представлен широкими слабоструктурированными линиями с локальными максимумами на энергиях фотонов $\sim 492.3$ эВ и $\sim 500$ эВ. Кроме того, присутствуют достаточно высокоинтенсивные «вакансионные» максимумы $\left(\mathbf{A}_{1}\right)$ и (C) [21-23]. Спектр поглощения М-края олова с аналогичной формой приведен в работе [22], где изучались сплошные тонкие пленки оксида олова, полученные методом магнетронного распыления.

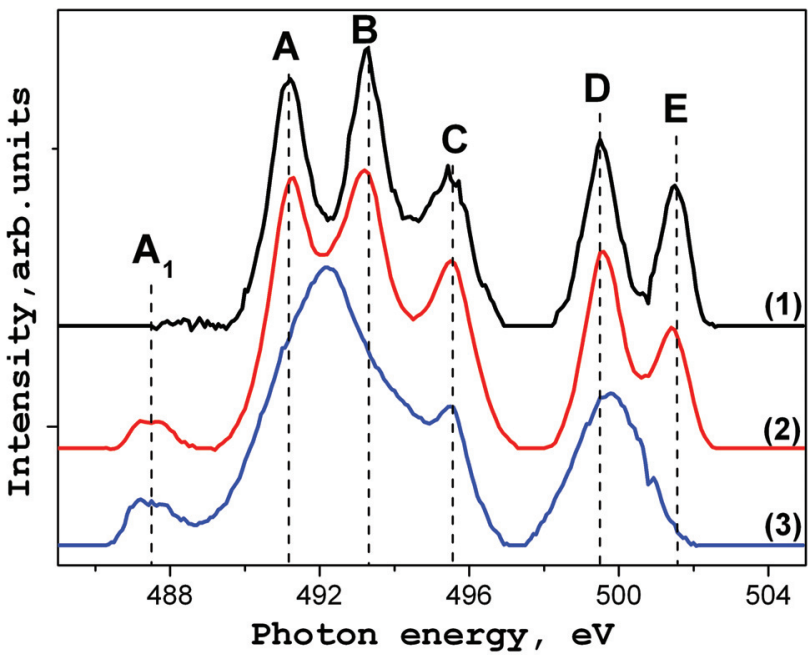

Рис. 5. Спектры XANES Sn M-края: 1 - порошка кристаллического $\mathrm{SnO}_{2}$; 2 - композита, сформированного методом химического осаждения; 3 - композита, сформированного методом магнетронного распыления [Fig. 5. XANES Sn M-edge spectra: 1 - crystalline $\mathrm{SnO}_{2}$ powder; 2 - composite formed by the chemical gas-phase deposition method; 3 - composite formed by the magnetron sputtering method]

Авторы указанной работы показали, что полученные пленки были представлены смесью оксидов олова различного состава и структуры: в них присутствует монооксид олова $\mathrm{SnO}$, а также диоксид олова с тетрагональной и орторомбической кристаллической решеткой. При этом основная часть олова в пленках присутствует в виде оксида $\mathrm{SnO}$ (до 65 \%). Это позволяет нам говорить, что в составе слоя оксида олова, покрывающего стенки МУНТ в композите, полученным методом магнетронного распыления, присутствуют оксиды $\mathrm{Sn}(\mathrm{II})$, наличие которых значительно повышает вероятность взаимодействия металлоксидного слоя с кислородсодержащими функциональными группами, присутствующими на внешних стенках МУНТ.

\section{ЗАКЛЮЧЕНИЕ}

Проведенное в работе исследование с использованием методов рентгеноэлектронного анализа (XPS, XANES), реализованных с применением синхротронного излучения, а также методов SEM и EDX позволило установить основные особенности формирования структуры и химического состояния композитов на основе МУНТ и оксида олова, полученных с применением различных способов осаждения оксида олова. Показано, что при использовании метода химического газофазного осаждения не происходит значительного изменения структуры внешних стенок МУНТ. Стен- 
ки нанотрубок слабо окисляются с формированием небольшого количества карбоксильных и карбонильных групп (COOH, C=O). Низкая функционализация поверхности приводит к формированию кластерной структуры композита. На поверхности МУНТ формируются отдельные кластеры кристаллического диоксида олова, слабо взаимодействующие с поверхностью МУНТ. Местами для первоначального закрепления оксида олова выступают существующие на поверхности МУНТ структурные и топологические дефекты.

При формировании композитов $\mathrm{SnO}_{\mathrm{x}} / \mathrm{MУHT}$ методом магнетронного распыления происходит значительное изменение структурно-химического состояния стенок МУНТ. Энергетическое воздействие осаждаемых атомов $\mathrm{Sn}$, а также обратно отраженных атомов и ионов рабочего газа, приводит к формированию структурных дефектов в стенках МУНТ: нескоординированных атомов углерода, адатомов и оборванных связей. Это в итоге приводит к значительной функционализации внешних стенок углеродных нанотрубок с закреплением большого количества кислородсодержащих групп различного состава: $\mathrm{C}-\mathrm{OH}, \mathrm{C}=\mathrm{O}, \mathrm{COOH}$, $\mathrm{C}-\mathrm{O}, \mathrm{C}-\mathrm{O}-\mathrm{C}, \mathrm{CO}_{3}$ и др., которые могут выступать в качестве центров ковалентного взаимодействия с оксидом металла. Анализ морфологии композитов методом SEM показал высокую межфазную адгезию оксида олова к стенкам МУНТ. Установлено, что в составе металлоксидного слоя, покрывающего МУНТ, присутствуют оксиды $\mathrm{Sn}(\mathrm{II})$, что повышает вероятность химического взаимодействия на межфазных интерфейсах композита.

Таким образом, полученные результаты позволили установить основные механизмы формирования структуры композитов $\mathrm{SnO}_{\mathrm{x}}$ /МУНТ при использовании методов химического газофазного осаждения и магнетронного распыления и в дальнейшем могут быть использованы при разработке композитных материалов на основе углеродных нанотрубок и оксидов металлов с необходимой структурой и комплексом физико-химических свойств.

Авторы выражают благодарность к. х. н. Стенькину Ю. А., Росликову В. Е. за проведение синтеза исходных МУНТ и композитов методом магнетронного распыления, а также Д. А. Смирновуи администрачии российско-германского канала синхротронного накопителя BESSY II (Берлин, Германия) за помощь в проведении измерений методами XPS и XANES. Авторы благодарят руководство ОмЦКП СО РАНза предоставление оборудования для исследования образиов методами SEM и EDX.
Работа выполнена по государственному заданию ОНЦ СО РАН в соответствии с Программой фундаментальных научных исследованийгосударственных академий наук на 2013-2020 годы по направлению II.9, проект № II.9.2.1 (номер госрегистрации в системе ЕГИСУ НИОКТР АААА-А17117041210227-8), а также при частичной поддержке гранта РФФИ № 18-32-00233 мол_а, в части анализа композитов методом SEM.

\section{СПИСОК ЛИТЕРАТУРЫ}

1. Манякин М. Д., Курганский С. И., Дубровский О. И., Чувенкова О. А., Лихачев Е. Р., Коюда Д. А., Домашевская Э. П., Овсянников Р., Турищев С. Ю. // Конденсированные среды и межфазные гранищы, 2016, т. 18, № 3, с. 356-366.

2. Feng L., Xuan Z., Ji S., Min W., Zhao H., Gao H. // Int. J. Electrochem. Sci., 2015, vol. 10, pp. 2370-2376.

3. Раков Э. Г. // Успехи химии, 2001, т. 70, № 10, c. 934-973.

4. Mallakpour S., Khadem E. // Chemical Engineering Journal, 2016, vol. 302, pp. 344-367. DOI: 10.1016/j. cej.2016.05.038

5. Сивков В. Н., Объедков А. М., Петрова О. В., Некипелов С. В., Кремлев К. В., Каверин Б. С., Семенов Н. М., Гусев С. А. // ФTT, 2015, т. 57, №. 1, с. 185-191.

6. Nesov S. N., Korusenko P. M., Povoroznyuk S. N., Bolotov V. V., Knyazev E. V., Smirnov D. A. // Nuclear Instruments and Methods in Physics Research B., 2017, vol. 410, № 1, pp. 222-229. DOI: $10.1016 / \mathrm{j}$. nimb.2017.08.040

7. Несов С. Н., Корусенко П. М., Болотов В. В., Поворознюк С. Н., Смирнов Д. А. // ФТТ, 2017, т. 59, № 10, c. 2006-2010. DOI: 10.21883/FTT.2017.10.44972.126

8. Чувенкова О. А., Домашевская Э. П., Рябцев С. В., Юраков Ю. А., Высоцкий Д. В., Вилков О. Ю., Овсянников Р. Ю., Турищев С. Ю. // Конденсированные среды и межфазные гранииы, 2013, т. 15, № 2, с. 184-194.

9. Rahmandoust M., Ayatollahi M. R. // Advanced Structured Materials, 2016, Vol. 39, p. 1-220. DOI: 10.1007/978-3-319-00251-4

10. Бржезинская М. М., Виноградов Н. А., Мурадян В. Е., Шульга Ю. М., Полякова Н. В., Виноградов А. С. // ФTT, 2008, т. 50, № 3, с. 565-571.

11. Fedoseeva Yu. V., Bulusheva L. G., Okotrub A. V., Kanygin M. A., Gorodetskiy D. V., Asanov I. P., Vyalikh D. V., Puzyr A. P., Bondar V. S. // Scientific Report, 2015, vol. 5, pp. 9379(7). DOI: 10.1038/srep09379

12. Brzhezinskaya M. M., Vinogradov A. S., Krestinin A. V., Zvereva G. I., Kharitonov A. P., Kulakova I. I. // Phys. Solid State, 2010, vol. 52, no. 4, pp. 876-883. DOI: https://doi.org/10.1134/S1063783410040323

13. Gandhiraman R. P., Nordlund D., Javier C., Koehne J. E., Chen B., Meyyappan M. // Journal of Physical Chemistry C, 2014, vol. 118, pp. 18706-18712. DOI: 10.1021/jp503941t 
14. Wang L., Han J., Zhu Y., Zhou R., Jaye C., Liu H., Li Z., Taylor G. T., Fischer D. A., Appenzeller J., Wong S. S. // Journal of Physical Chemistry C, 2015, vol. 119, pp. 26327-26338. DOI: 10.1021/acs.jpcc.5b08681

15. Fedoseeva Yu. V., Okotrub A. V., Bulusheva L. G., Maksimovskiy E. A., Senkovskiy B. V., Borzdov Yu. M., Palyanov Yu. N. // Diamond \& Related Materials, 2016, vol. 70, pp. 46-51. DOI: 10.1016/j.diamond.2016.09.023

16. Zhang X., Zhou J., Song H., Chen X., Fedoseeva Yu. V., Okotrub A. V., Bulusheva L. G. // ACS Applied Materials \& Interfaces, 2014, vol. 6, № 19, pp. 1723617244. DOI: $10.1021 / \mathrm{am} 505186 \mathrm{a}$

17. Zhou G., Wang D., Yin L., Li N., Li F., Cheng H. // ACS Nano, 2012, vol. 6, № 4, pp. 3214-3223. DOI: 10.1021/ nn300098m

18. Alexeeva O. K., Fateev V. N. // International Journal of Hydrogen Energy, 2016, vol. 41, № 5, pp. 3373-3386. DOI: $10.1016 /$ j.ijhydene.2015.12.147
19. Кузьмичёв А. И. Магнетронные распьлительные системы. Киев, Аверс, 2008, 244 с.

20. Yang G., Kim B., Kim K., Han J. W., Kim J. // RSC Advances, 2015, vol. 5, pp. 31861-31865. DOI: 10.1039/ C5RA03551A

21. Турищев С. Ю., Терехов В. А., Тонких А. А., Захаров Н. Д., Анисимов А. В., Чувенкова О. А., Юраков Ю. А., Паринова Е. В., Коюда Д. А., Сеньковский Б. В. // Конденсированные среды и межфазные гранииы, 2016, т. 18, № 2, с. 265-274.

22. Manyakin M. D., Kurganskii S. I., Dubrovskii O. I., Chuvenkova O. A., Domashevskaya E. P., Ryabtsev S. V., Ovsyannikov R., Turishchev S. Yu. // Computational Materials Science, 2016, vol. 121, pp. 119-123. DOI: 10.1016/ j.commatsci.2016.04.034

23. Несов С. Н., Болотов В. В., Корусенко П. М., Поворознюк С. Н., Вилков О. Ю. // ФТТ, 2016, т. 58, № 5, c. 966-971.

\title{
STRUCTURE OF COMPOSITES BASED ON MULTI-WALL CARBON NANOTUBES AND TIN OXIDE
}

\author{
C2018 S. N. Nesov' ${ }^{1}$, P. M. Korusenko ${ }^{1}$, V. V. Bolotov ${ }^{1}$, S. N. Povoroznyuk ${ }^{1,2}$, K. E. Ivlev ${ }^{1}$ \\ ${ }^{1}$ Omsk Scientific Center, Siberian Branch of the Russian Academy of Sciences, 15 Karl Marx ave., 644040 Omsk, Russia \\ ${ }^{2}$ Omsk State Technical University, 11 Mira ave., 644050 Omsk, Russia \\ e-mail:nesov55@mail.ru
}

Received 27.03.2018

\begin{abstract}
The main purpose of this work was to study the structure, morphology, and composition of composites based on multi-walled carbon nanotubes (MWCNTs) and tin oxide obtained by the methods of chemical vapour deposition and magnetron sputtering. X-ray photoelectron spectroscopy (XPS), X-ray absorption spectroscopy (XANES), scanning electron microscopy (SEM), energy dispersive X-ray spectroscopy (EDX) were used to analyse the structure and composition of the obtained composites. It is shown that the morphology and structure of the formed composites depend substantially on the change in the structure and chemical state of the outer walls of MWCNTs during the process of depositing tin oxide on their surface.

It is established that when using the method of chemical vapour deposition, no significant changes in the crystal structure and chemical state of carbon in the walls of the MWCNTs are observed. The MWCNTs surface weakly oxidises with the formation of carboxyl and carbonyl groups $(\mathrm{C}=\mathrm{O}$, $\mathrm{COOH})$. As a result, tin oxide is distributed along the surface of the MWCNTs as separate clusters that interact weakly with the outer walls of carbon nanotubes. It is shown that tin oxide in clusters is mainly represented by defective crystalline $\mathrm{SnO}_{2}$

The magnetron sputtering method contributes to the formation of a large number of structural defects and a considerable oxidation of the MWCNTs surface with the formation of functional oxygen-containing groups of different composition ( $\mathrm{C}-\mathrm{OH}, \mathrm{C}=\mathrm{O}, \mathrm{COOH}, \mathrm{C}-\mathrm{O}-\mathrm{C}$, - $\mathrm{CO} 3$, etc.). Significant functionalization of the walls of carbon nanotubes leads to the chemical interaction between tin oxide and the surface of MWCNTs. This results in an increase in interracial adhesion in the composite, whereby the tin oxide uniformly covers the walls of the MWCNTs as a continuous layer.

The obtained results can be used in the development of composites based on carbon nanotubes and metal oxides with the required structure and a set of physicochemical characteristics.
\end{abstract}

Keywords: multi-walled carbon nanotubes, composite, tin oxide, chemical vapour deposition, magnetron sputtering, X-ray spectroscopy.

DOI: https://doi.org/10.17308/kcmf.2018.20/515 


\section{С. Н. НЕСОВ, П. М. КОРУСЕНКО, В. В. БОЛОТОВ, С. Н. ПОВОРОЗНЮК, К. Е ИВЛЕВ}

\section{ACKNOWLEDGEMENTS}

The authors would like to thank Yu.A. Stenkin, PhD in Chemistry, and V.Ye. Roslikov for synthesising original MWCNTs and composites by magnetron sputtering and D.A. Smirnova and the administration of Russian and German source of synchrotron radiation BESSY II (Berlin, Germany) for their help in conducting measurements by the XPS and XANES methods. The authors would like to thank Omsk Regional Centre for Collective Use of the Siberian Branch of the Russian Academy of Sciences for the equipment to study samples by SEM and EDX methods.

The work was performed under the state task of Omsk Regional Centre for Collective Use of the Siberian Branch of the Russian Academy of Sciences in accordance with the Programme of Fundamental Research of the Russian Academies of Sciences for 20132020 in area II.9, project II.9.2.1 (state registration number in the integrated national information system of research, development, and engineering projects AAA-A17-117041210227-8), and also was partial supported by a grant from the Russian Foundation for $\mathrm{Ba}$ sic Research no. 18-32-00233 mol_a, regarding the analysis of composites by the SEM method.

\section{REFERENCES}

1. Manyakin M. D., Kurganskii S. I., Dubrovskii O. I., Chuvenkova O. A., Likhachev E. R., Koyuda D. A., Domashevskaya E. P., Ovsyannikov R., Turishchev S. Yu. Condensed Matter and Interphases, 2016, vol. 18, no. 3, pp. 356-366. Available at: http://www.kcmf.vsu.ru/ resources/t_18_3_2016_006.pdf (in Russ.)

2. Feng L., Xuan Z., Ji S., Min W., Zhao H., Gao H. Int. J. Electrochem. Sci., 2015, vol. 10, pp. 2370-2376.

3. Rakov E. G. Russ. Chem. Rev., 2001, vol. 70, no. 10, pp. 827-863. DOI: https://doi.org/10.1070/ RC2001v070n10ABEH000660

4. Mallakpour S., Khadem E. Chemical Engineering Journal, 2016, vol. 302, pp. 344-367. DOI: 10.1016/j. cej.2016.05.038

5. Sivkov V. N., Ob'edkov A. M., Petrova O. V., Nekipelov S. V., Kremlev K.V., Kaverin B. S., Semenov N. M., Gusev C. A. Phys. Solid State, 2015, vol. 57, no. 1, pp. $197-$ 204. https://doi.org/10.1134/S1063783415010291

6. Nesov S. N., Korusenko P. M., Povoroznyuk S. N., Bolotov V. V., Knyazev E. V., Smirnov D. A. Nuclear Instruments and Methods in Physics Research B., 2017, vol. 410, no. 1, pp. 222-229. DOI: 10.1016/j.nimb.2017.08.040

7. Nesov S. N., Korusenko P. M., Bolotov V. V., Povoroznjuk S. N., Smirnov D. A. Phys. Solid State, 2017, vol. 59, no.10, pp. 2030-2035. https://doi.org/10.1134/ S1063783417100286

8. Chuvenkova O. A., Domashevskaya E. P., Ryabtsev S. V., Yurakov Yu. A., Vysotskii D. V., VilkovO. Yu., Ovsyannikov R. Yu., Turishchev S. Yu. Condensed Matter and Interphases, 2013, vol. 15, no. 2, pp. 184-194. Available at: http://www.kcmf.vsu. ru/resources/t_15_2_2013_016.pdf (in Russ.)

9. Rahmandoust M., Ayatollahi M. R. Advanced Structured Materials, 2016, vol. 39, p. 1-220. DOI: 10.1007/9783-319-00251-4

10. Brzhezinskaja M. M., Vinogradov N. A., Muradjan V. E., Shul'ga Ju. M., Poljakova N. V., Vinogradov A. S. Phys. Solid State, 2008, vol. 50, no. 3, pp. 587-594. DOI: https://doi.org/10.1134/S1063783408030323

11. Fedoseeva Yu. V., Bulusheva L. G., Okotrub A. V., Kanygin M. A., Gorodetskiy D. V., Asanov I. P., Vyalikh D. V., Puzyr A. P., Bondar V. S. Scientific Report, 2015, vol. 5, pp. 9379(7). DOI: 10.1038/srep09379

12. Brzhezinskaya M. M., Vinogradov A. S., Krestinin A. V., Zvereva G. I., Kharitonov A. P., Kulakova I. I. Phys. Solid State, 2010, vol. 52, no. 4, pp. 876-883. DOI: https://doi.org/10.1134/S1063783410040323

13. Gandhiraman R. P., Nordlund D., Javier C., Koehne J. E., Chen B., Meyyappan M. Journal of Physical Chemistry C, 2014, vol. 118, pp. 18706-18712. DOI: 10.1021/jp503941t

14. Wang L., Han J., Zhu Y., Zhou R., Jaye C., Liu H., Li Z., Taylor G. T., Fischer D. A., Appenzeller J., Wong S. S. Journal of Physical Chemistry C, 2015, vol. 119, pp. $26327-$ 26338. DOI: $10.1021 /$ acs.jpcc.5b08681

15. Fedoseeva Yu. V., Okotrub A. V., Bulusheva L. G., Maksimovskiy E. A., Senkovskiy B. V., Borzdov Yu. M., Palyanov Yu. N. Diamond \& Related Materials, 2016, vol. 70, pp. 46-51. DOI: 10.1016/j.diamond.2016.09.023

16. Zhang X., Zhou J., Song H., Chen X., Fedoseeva Yu. V., Okotrub A. V., Bulusheva L. G. ACS Applied Materials \& Interfaces, 2014, vol. 6, no. 19, pp. 17236 17244. DOI: $10.1021 / \mathrm{am} 505186 \mathrm{a}$

17. Zhou G., Wang D., Yin L., Li N., Li F., Cheng H. ACS Nano, 2012, vol. 6, no. 4, pp. 3214-3223. DOI: $10.1021 / \mathrm{nn} 300098 \mathrm{~m}$

18. Alexeeva O. K., Fateev V. N. International Journal of Hydrogen Energy, 2016, vol. 41, no. 5, pp. 3373-3386. DOI: 10.1016/j.ijhydene.2015.12.147

19. Kuzmichev A. I. Magnetronnye raspylitel'nye sistemy [Magnetron Sputtering Systems]. Kiev, Avers Publ., 2008, 244 p. (in Russ.)

20. Yang G., Kim B., Kim K., Han J. W., Kim J. RSC Advances, 2015, vol. 5, pp. 31861-31865. DOI: 10.1039/ C5RA03551A

21. Turishchev S. Yu., Terekhov V. A., Tonkikh A. A., Zakharov N. D., Anisimov A. V., Chuvenkova O. A., Yurakov Yu. A., Parinova E. V., Koyuda D. A., Senkovskii B. V. Condensed Matter and Interphases, 2016, vol. 18, no. 2, pp. 265-274. Available at: http://www.kcmf.vsu.ru/resources/t_18_2_2016_011.pdf (in Russ.)

22. Manyakin M. D., Kurganskii S. I., Dubrovskii O. I., Chuvenkova O. A., Domashevskaya E. P., Ryabtsev S. V., Ovsyannikov R., Turishchev S. Yu. Computational Materials Science, 2016, vol. 121, pp. 119-123. DOI: 10.1016/ j.commatsci.2016.04.034

23. Nesov S. N., Bolotov V. V., Korusenko P. M., Povoroznyuk S. N., Vilkov O. Yu. Phys. Solid State, 2016, vol. 58, no. 5, pp. 997-1003. DOI: https://doi.org/10.1134/ S1063783416050164 
Несов Сергей Николаевич - м. н. с. лаборатории физики наноматериалов и гетероструктур ОНЦ СО РАН; тел.: +7(913) 6639018, e-mail: nesov55@mail.ru

Корусенко Петр Михайлович - м. н. с. лаборатории физики наноматериалов и гетероструктур Омского научного центра СО РАН (ОНЦ СО РАН); тел.: +7(983) 6214220, e-mail: korusenko@ obisp.oscsbras.ru

Болотов Валерий Викторович - Д. ф.-м. н., профессор, заведующий лабораторией физики наноматериалов и гетероструктур ОНЦ СО РАН; тел.: +7(3812) 560174, e-mail: bolotov@obisp.oscsbras.ru

Поворознюк Сергей Николаевич - к. т. н., доцент, с. н. с. лаборатории физики наноматериалов и гетероструктур ОНЦ СО РАН, доцент кафедры «Машиностроение и материаловедение» Омского государственного технического университета; тел.: +7(913) 1422386, e-mail: povorozn@obisp. oscsbras.ru

Ивлев Константин Евгеньевич - м. н. с. лаборатории физики наноматериалов и гетероструктур Омского научного центра СО РАН (ОНЦ СО РАН); тел.: +7(3812) 560174, e-mail: ivlev@obisp. oscsbras.ru
Sergey N. Nesov-Junior Researcher, Laboratory of Physics of Nanomaterials and Heterostructures, Omsk Scientific Center SB RAS; tel.: +7(913) 6639018, email: nesov55@mail.ru

Petr M. Korusenko - Junior Researcher, Laboratory of Physics of Nanomaterials and Heterostructures, Omsk Scientific Center SB RAS; tel.: +7(983) 6214220, e-mail: korusenko@obisp.oscsbras.ru

Valery V. Bolotov - Dr. Sci. (Phys.-Math.), Professor, Head of Laboratory of Physics of Nanomaterials and Heterostructures, Omsk Scientific Center SB RAS; tel.: +7(3812) 560174, e-mail: bolotov@obisp.oscsbras.ru

Sergey N. Povoroznyuk - Cand. Sci. (Eng.)., Associate Professor, Senior Researcher of the Laboratory of Physics of Nanomaterials and Heterostructures, Omsk Scientific Center SB RAS; Associate Professor of the Department of "Mechanical Engineering and Materials Science" of the Omsk State Technical University; tel.: +7(913) 1422386, e-mail: povorozn@ obisp.oscsbras.ru

Konstantin E. Ivlev - Junior Researcher, Laboratory of Physics of Nanomaterials and Heterostructures, Omsk Scientific Center SB RAS; tel.: +7(3812) 560174, e-mail: ivlev@obisp.oscsbras.ru 